\title{
CIÊNCIA'NATURA
}

\section{Automatic classification of laparos call and playback tests at cuniculture nests}

Nilson Evilásio Souza Filho ${ }^{1}$, Vinícius Mourão Alves de Souza², Ana Carolina Kohlrausch Klinger ${ }^{3}$ e Geni Salete Pinto de Toledo ${ }^{3}$

\footnotetext{
${ }^{1}$ Engenharia Acústica, Centro de Tecnologia, Universidade Federal de Santa Maria, Santa Maria, RS, Brazil

${ }^{2}$ Instituto de Ciências Matemáticas e de Computação, Universidade de São Paulo, São Carlos, São Paulo, Brazil

${ }^{3}$ Departamento de Zootecnia, Universidade Federal de Santa Maria, Santa Maria, RS, Brazil
}

\begin{abstract}
The vocal behavior of rabbit pups was monitored during their first 15 days of life. It was possible to estimate the average of vocalizations issued in the nest by correlation calculations applied to spectrographic images. We performed experimental tests of playback and observed the behavior between the offspring and the doe during the period of lactation. The vocalizations can be important in pup recognition and consequently, stimulate the doe to nurse their offspring, decreasing the rate of mortality in the breeding phase.
\end{abstract}

Keywords: Template matching. Rabbit pup vocalization. Rabbit behavior. 


\section{1 introduction}

Laparos are the pups of rabbits that accompany them from birth to weaning during the lactation period of one month. They are born without hair, with eyes and ears sealed, limited motor coordination and incapacity of thermoregulation (Hudson and Distel, 1982). It is known that the breeding phase is when the laparos are more fragile, and this phase presents high rates of mortality (Hudson and Distel, 1982). Rabbits present a peculiar behavior and they are still less studied when compared to other animal species pups (Hudson and Distel, 1982). Understanding the behavior of litters assists the identification of anomalous signs, as situations of stress that may contribute to the mortality rate in the breeding phase.

The means of communication in most mammals species include visual and olfactory input, body contact, and pheromones (Liu et al., 2013; Rödel et al., 2013). Vocal communication has the special importance in mother-offspring interactions in many mammals. In rabbits, pup distress call is the main trigger to parental care, essential for offspring survival and development (Rödel et al., 2013). As in any communication system, the acoustic signals of animal communication need to keep the information they carry throughout the three stages of communication: emission, transmission and reception.

The signal should therefore arrive at the receiver so that its function is captured and identified. The emission and reception of a signal of communication are conducted through specialized anatomical and physiological capacities that are appropriate to the modality of the signal and the environment they live in the animal in question (Da Silva et al., 2000).

The communication is often reaching predetermined outcomes. But for that, it is necessary to set goals and measurable terms in which the result is wanted to achieve with communication. It should be established, in behavioral terms (desired responses) which will indicate whether there has been a change in desired behavior and, therefore, the communication was efficient. When this does not occur, it is said that communication failed (Da Silva et al., 2000).

The communication between parent and offspring is important to adjust the care the offspring needs. Signals from the young may act to indicate a pup's immediate need, such as for thermoregulation or food (Liu et al., 2013). Few studies have been conducted to investigate the communication pattern used by rabbits in commercial breeding (Schuh et al., 2004).

Acoustic signals are generally not stationary. For the analysis of non-stationary signals, a commonly used method is that which describes the signal in both time and frequency. As the name implies, the time-frequency analysis associates a temporal signal (one-dimensional function of time) with an image (a two-dimensional function of time and frequency) which shows spectral components of the signal as a function of time. Conceptually, it is possible to think in this mapping as a time-varying spectral representation of the signal. This representation is analogous to a musical score, with the two main axes represented by time and frequency (Souza Filho et al., 2014).

The value of time-frequency representation of signal provides an indication of the specific times at which certain spectral components of the signal are observed. One of the tools that are used in processing non-stationary signals, with a multitude of applications in audio, is the Short Time Fourier Transform (STFT). The STFT of a signal is defined as the Fourier transform of the windowed signal, from which is obtained the spectrogram.

The spectrogram represents a simple but powerful extension of the classical Fourier theory. In physical terms, the spectrogram provides a measure of the signal energy in the time-frequency plane. The spectrogram is an image that visually represents the frequency variation of a signal over time, and simultaneously gives the energy of signal and describes perfectly the details of the signal in question.

We proposed a method based on correlation calculations applied to images, a technique called Spectrographic Image Template Matching (SITM) (Souza Filho et al., 2014) find the laparos calls in 360h recording for each nest. Four standard cuniculture nests were monitored. The SITM stores correlation data of continuous units visualized in the spectrogram, and used it for automating the process of classification among them. The automatic classification of sound patterns is extremely useful because the precision and the large number of data processed almost simultaneously, generates results that a human observer could never achieve so quickly (Souza Filho et al., 2014).

In this study, we try to extract the pattern of vocalizations into the nest and observe the consequences of its use during the lactation period. First, we performed sound monitoring of four nests during two weeks of lactation, considering typical conditions of commercial reproduction. Among the known methods for sound pattern recognition (Souza Filho et al., 2014; Souza et al., 2015), we used the Spectral Image Template Matching (SITM) to quantify the number of pups from each nest. Then, we chose the pup calls of three nests for the playback experiments and observed the behavior of the litters through vocal communication between pups and the doe. We report the maternal behavior of rabbits in relation to vocal communication of pups in the nest.

\section{Methods}

\subsection{Experimental arrangements}

The experiments arrangements were conducted in the Cunicultura, Departamento de Zootecnia, Universidade Federal de Santa Maria, Brazil. The investigation was carried out in 2016 between May and June. The European rabbits, Oryctolagus 
cuniculus (Linnaeus, 1758), were kept in anodized aluminum cages equipped with wooden nest boxes. The first weeks of lactation could be monitored by a recording system with microphones.

\subsubsection{Sound monitoring}

The vocalizations of the pups in four nest were continuously recorded over a 24 hour period with four microphones, two measurement microphones (Superlux, ECM-999) and two condenser microphones (Behringer, C2), both pairs with a frequency range of 40 to $20000 \mathrm{~Hz}$ which was fixed in a hole on top of the nest. The microphones were powered by a pre-amplifier audio interface (Presonus Firepod) connected to a computer via firewire (IEEE1394). With this audio system, we could monitor eight nests simultaneously, with the possibility of expanding eight more nests for each firewire interface.

\subsubsection{Classification of pups call by SITM}

The correlation between two signals is given by Equation 1:

$$
g(t) \circ h(t)=\int_{-\infty}^{\infty} g(\tau) * w(t+\tau) d t .
$$

The expression (1) multiplies two temporal series, being the second $\mathrm{h}(\mathrm{t})$ shifted in time by an amount $\mathrm{t}(\mathrm{known}$ as delay factor), and integrates the resulting signal. The inner product property suggests an interpretation of the mathematical correlation as a measure of similarity between two functions in relation to a number of relative displacements between them.

In this type of analysis the peaks are clearly identified and interpreted as follows: the correlation $(\mathrm{g} O \mathrm{~h})(\mathrm{t}) \mathrm{on}$ makes $\mathrm{h}(\mathrm{t})$ glide along the function $\mathrm{g}(\mathrm{t})$ and calculate the inner product for each of these situations, so that each intensity correlation gives an indication of similarity between functions. In other words, the correlation allows searching for positions where two functions are more similar. Template Matching seeks to locate a large image g the occurrence of similar objects to a small image h, the mold (or template). When calculating the correlation between the large picture and the mold, the positions at which the large image resembles the mold will have high correlation value. Thus, a search for the image of the extreme positions provides correlation, and the value of these extremes will provide the degree of similarity (Cesar Jr, Marcondes R. and Costa L.).

The pup call templates (individual call vocalizations of the pups) were recorded with a manual recorder (Tascam, Dr100 MkII), arbitrarily on the third day of life. Recordings were sampled at $44.1 \mathrm{kHz}$ with a resolution of 32 bit. These templates were used to recognize the call of the rabbit pups in the nest monitoring recordings and to playback tests.

\subsubsection{Playback Experiment}

All playback files were normalized to peak amplitude. Were used different vocalizations of three nest to perform the playback experiment. The spectrograms vocalizations used for playback embodiment are shown in figure 1. All audios have around $7 \mathrm{~s}$ and the sonograms are set to show frequencies of 0 to $5 \mathrm{kHz}$. To avoid pseudoreplication (Kroodsma et al., 2001), we prepared for each female a playback file with calls from a different individual. Pups call were played at $45 \mathrm{~dB}$, corresponding to their natural volume. Seven seconds of a pure tone of $440 \mathrm{~Hz}$ was used as a control stimulus (45 dB). We standardized the amplitude of the stimuli, using the 'normalize' function in the software Cool Edit. Playbacks were played directly from a smartphone, connected to a pre-amplifier, in a rectangular speaker of 2 X 3.5 inch with $5 \mathrm{~W}$ and $16 \Omega$, camouflaged in the nest. The calls were broadcasted with a peak sound pressure level (SPL) of $45 \mathrm{~dB}$ as measured at $1.0 \mathrm{~m}$ distance from the loudspeaker with a sound level meter. Each female received one playback trial of pups call. The spectrographic evaluation was conducted with 4 litters over 15 days.

One person played the audios and another person wrote down the behavioral responses. Before playing the playbacks, it was assigned non-informative codes to all sound files for observer and it was played them for each female. With this procedure, we avoid the observer knowing which playback is in use. The conditions made it possible to test if the nursing time can be induced by calls. The experiments were performed twice a day for six days, from the fourth day of life of the pups.

The behavior of mother and offspring was observed, and it was checked if the doe was induced to vigilance; return to nest, or nursing. Animals were considered to be vigilant when they abruptly raised the head above shoulder height while maintaining the feeding posture, or adopted an upright posture, either quadrupedal or bipedal, lifted the ears, often looked around and stopped all current activities. Return to nest or exploration at the burrow was defined as sniffing with head down to the ground with frequent head movements to left and right, while the animal was moving slowly or stopped moving forward (Rödel et al., 2013). Nursing is considered when the doe stayed in a position allowing the pup to suckle, as the doe's ability to actively eject milk.

To analyze the behavioral response data, we consider that the occurrences of mother's nursing, returning to the nest or vigilance responses were used as dichotomous dependent variables. First was comparing the responses of these three variables with sound control (fixed factor with two levels). Then, was compared the behavioral responses to playbacks call. 


\section{Results}

\subsection{SITM analysis of sound monitoring}

Were performed $360 \mathrm{~h}$ of recordings in four nests simultaneously, $1440 \mathrm{~h}$ of total recording. Rabbit pups vocalize in the two first weeks of life. The calls are uttering low whistles (duration $0.05-150 \mathrm{~s}$; frequency range $0.50-4 \mathrm{kHz}$ ) and whistles (duration $0.15-550 \mathrm{~s}$; frequency range $0.50-30 \mathrm{kHz}$ ) and nuzzled which frequently occur together in bouts. The spectrographic evaluation was conducted with 4 litters over 15 days. The mean litter size was $(4.5 \pm 0.5)$ pups. The quantitative analysis performed by SITM showed that an average of 53 communication calls were issued in the 15 -day period, or 13.3 calls/day in each litter, approximately 3 calls/pup in 24 hours. Over the 53 communication signs, $76 \%$ were issued in the first week and $34 \%$ in the second week.

\subsection{Response to the playback experiment}

The conditions that we define in the playback experiment made it possible test if the nursing time can be induced by calls from their own pup or by calls from non-consanguineous pups. When using the calls of the pup as the main mechanism to induce the nursing time, in this work, only when nursing occurred was considered as induced nursing time and the observer scored simply YES or NO after the experiment.

Table 1 shows the results of playback experiments in the nests 1 and 2 . Figure 1 shows the spectrogram of pup calls used for playback experiments. Table 1 shows the responses of the doe to the playback tests.

Table 1 indicates that the mother rabbit does not respond to any signal. With playback of $440 \mathrm{~Hz}$ control signal, it presented the vigilance behavior in $18 \%$ of the cases, returned to the nest $9.1 \%$ and did not nurse. While for pups call, the doe always shows the behavior of vigilance, $80 \%$ returned to the nest and nursing $18 \%$ of times.

Table 1 also presents that the does always show the behavior of vigilance for any call, but for own pup call, the does always return to the nest and $70 \%$ of the times they nursing the offspring. While for calls of non-consanguineous pups, such rabbits returned to nest $75 \%$ but did not nurse the offspring.

Table 1 - Results of the playback experiment

\begin{tabular}{|c|c|c|c|c|c|}
\hline Playback control & Doe of nest $A$ & Doe of nest B & Playback call & Doe of nest $A$ & Doe of nest B \\
\hline $440 \mathrm{~Hz}$ & $\begin{array}{l}\text { 18/06/2016; 8am } \\
\text { Vigilance }[\mathrm{X}] \\
\text { Return to nest [ ] } \\
\text { Nursing [ ] }\end{array}$ & $\begin{array}{l}\text { 19/06/2016; 8am } \\
\text { Vigilance [ ] } \\
\text { Return to nest [ ] } \\
\text { Nursing [ ] }\end{array}$ & $\mathbf{A}$ & $\begin{array}{l}\text { 18/06/2016; 8am } \\
\text { Vigilance }[\mathrm{X}] \\
\text { Return to nest }[\mathrm{X}] \\
\text { Nursing }[\mathrm{X}]\end{array}$ & $\begin{array}{l}\text { 19/06/2016; 8am } \\
\text { Vigilance }[\mathrm{X}] \\
\text { Return to nest }[\mathrm{X}] \\
\text { Nursing }[\mathrm{]}\end{array}$ \\
\hline $440 \mathrm{~Hz}$ & & $\begin{array}{l}\text { 19/06/2016; 7pm } \\
\text { Vigilance [ ] } \\
\text { Return to nest [ ] } \\
\text { Nursing [ ] }\end{array}$ & $\mathbf{A}$ & & $\begin{array}{l}\text { 19/06/2016; } 7 \mathrm{pm} \\
\text { Vigilance }[\mathrm{X}] \\
\text { Return to nest }[\mathrm{X}] \\
\text { Nursing }[\mathrm{]}\end{array}$ \\
\hline $440 \mathrm{~Hz}$ & $\begin{array}{l}\text { 20/06/2016; } 7 \mathrm{pm} \\
\text { Vigilance [X] } \\
\text { Return to nest [ ] } \\
\text { Nursing [ ] }\end{array}$ & $\begin{array}{l}\text { 21/06/2016; 8am } \\
\text { Vigilance [ ] } \\
\text { Return to nest [ ] } \\
\text { Nursing [ ] }\end{array}$ & B & $\begin{array}{l}\text { 20/06/2016; 8am } \\
\text { Vigilance }[\mathrm{X}] \\
\text { Return to nest }[\mathrm{X}] \\
\text { Nursing }[\mathrm{]}\end{array}$ & $\begin{array}{c}\text { 21/06/2016; 8am } \\
\text { Vigilance }[\mathrm{X}] \\
\text { Return to nest }[\mathrm{X}] \\
\text { Nursing }[\mathrm{]}\end{array}$ \\
\hline $440 \mathrm{~Hz}$ & $\begin{array}{l}\text { 20/06/2016; } 7 \mathrm{pm} \\
\text { Vigilance }[\mathrm{X}] \\
\text { Return to nest [ ] } \\
\text { Nursing [ ] }\end{array}$ & $\begin{array}{l}\text { 21/06/2016; 5pm } \\
\text { Vigilance [ ] } \\
\text { Return to nest [ ] } \\
\text { Nursing [ ] }\end{array}$ & B & $\begin{array}{l}\text { 20/06/2016; } 7 \mathrm{pm} \\
\text { Vigilance }[\mathrm{X}] \\
\text { Return to nest }[\mathrm{X}] \\
\text { Nursing }[]\end{array}$ & $\begin{array}{l}\text { 23/06/2016; } 7 \mathrm{pm} \\
\text { Vigilance }[\mathrm{X}] \\
\text { Return to nest [ ] } \\
\text { Nursing [ ] }\end{array}$ \\
\hline $440 \mathrm{~Hz}$ & $\begin{array}{l}\text { 22/06/2016; 8am } \\
\text { Vigilance [ ] } \\
\text { Return to nest [ ] } \\
\text { Nursing [ ] }\end{array}$ & $\begin{array}{l}\text { 23/06/2016; 7pm } \\
\text { Vigilance [ ] } \\
\text { Return to nest [ ] } \\
\text { Nursing [ ] }\end{array}$ & $\mathbf{C}$ & $\begin{array}{l}\text { 22/06/2016; 8am } \\
\text { Vigilance }[\mathrm{X}] \\
\text { Return to nest }[\mathrm{X}] \\
\text { Nursing }[\mathrm{]}\end{array}$ & $\begin{array}{l}\text { 23/06/2016; 8am } \\
\text { Vigilance [X] } \\
\text { Return to nest [ ] } \\
\text { Nursing [ ] }\end{array}$ \\
\hline $440 \mathrm{~Hz}$ & $\begin{array}{l}\text { 22/06/2016; } 5 \mathrm{pm} \\
\text { Vigilance [ ] } \\
\text { Return to nest [ ] } \\
\text { Nursing [ ] }\end{array}$ & $\begin{array}{l}\text { 24/06/2016; 8am } \\
\text { Vigilance [X] } \\
\text { Return to nest [ ] } \\
\text { Nursing [ ] }\end{array}$ & C & $\begin{array}{l}\text { 22/06/2016; 5pm } \\
\text { Vigilance }[\mathrm{X}] \\
\text { Return to nest }[\mathrm{X}] \\
\text { Nursing }[\mathrm{]}\end{array}$ & $\begin{array}{l}\text { 24/06/2016; 8am } \\
\text { Vigilance [X] } \\
\text { Return to nest [ ] } \\
\text { Nursing [ ] }\end{array}$ \\
\hline
\end{tabular}


Figure 1 - Spectrogram of pups call used for playback experiments. (a) Call of individual pup of nest A; (b) Call of individual pup of nest B; (c) Call of individual pup of nest $\mathrm{C}$.

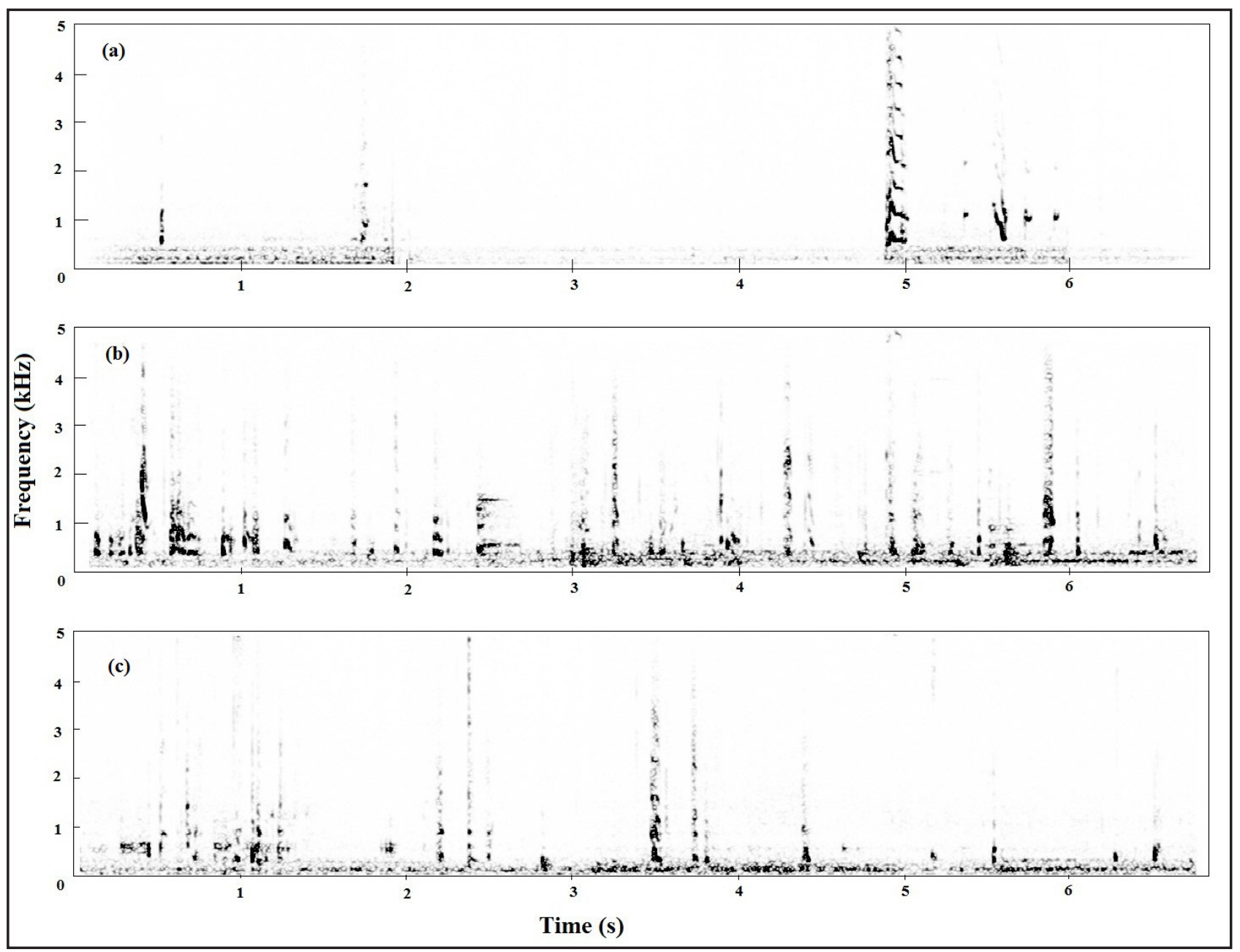

\section{Discussion}

In various species, offspring calls (distress cries, fear screams) are emitted in situations of direct threat when young are injured or at risk of being killed. Scientist already conducted playback experiments with animals of a field enclosure population to test whether pup distress vocalizations induce maternal behaviors indicative of offspring defense (Rödel et al., 2013). But they not used calls from the consanguineous pup.

We worked under commercial conditions of captivity. Four nests were monitored for 15 days. From the sound recordings, it was possible to estimate the average of calls issued in the nests using the SITM pattern recognition. It was determined that the pups issued on average 13.3 calls/day in each litter. Mothers leave their altricial young in a burrow and only visit them for a brief nursing, around 3 min once a day (Hudson and Distel, 1982). We used a vocal playback of non-consanguineous and consanguineous pups to stimulate the nursing time. The evidence of table 1 suggests the realization of new similar experiments with a larger sample, to study the cognitive relation between vocal communication and rabbits maternal care.

\section{Conclusions}

A vocal playback technique was used to stimulate the nursing time. Our playback experiments test show that acoustic cues are relevant in mother-pup Oryctolagus cuniculus communication. The vocalization of the pups cannot be the exclusive way to animates the doe nursing, but it was observed that the pups call can trigger this mechanism. This new concept of stimulation of nursing time by vocal reproduction of a pup may be useful as a control of malnutrition and mortality in the breeding phase. 


\section{Ethical approval}

All applicable international, national, and/or institutional guidelines for the care and use of animals were followed. No specific permissions were required under Brazilian law for this noninvasive study.

\section{Acknowledgment}

Capes. Fapesp. Prof. Lucio Strazzabosco Dorneles.

\section{References}

Cesar Jr, Marcondes R. and Costa L. Shape classification and analysis: theory and practice (2009), Crc Press.

Da Silva, M. L., Piqueira, J. R. C., Vielliard, J. M. (2000). Using shannon entropy on measuring the individual variability in the rufous-bellied thrush Turdus rufiventris vocal communication. Journal of Theoretical Biology, 207(1), 57-64.

Hudson, R., Distel, H. (1982). The pattern of behaviour of rabbit pups in the nest. Behaviour, 79(2), 255-271.

Kroodsma, D. E., Byers, B. E., Goodale, E., Johnson, S., Liu, W. C. (2001). Pseudoreplication in playback experiments, revisited a decade later.

Liu, H. X., Lopatina, O., Higashida, C., Fujimoto, H., Akther, S., Inzhutova, A., Liang, M., Zhong, J., Tsuji, T., Yoshihara, T., et al. (2013). Displays of paternal mouse pup retrieval following communicative interaction with maternal mates. Nature communications, 4,1346 .

Rödel, H. G., Landmann, C., Starkloff, A., Kunc, H. P., Hudson, R. (2013). Absentee mothering-not so absent? Responses of european rabbit (Oryctolagus cuniculus) mothers to pup distress calls. Ethology, 119(11), 1024-1033.

Schuh, D., Hoy, S., Selzer, D., et al. (2004). Vocalization of rabbit pups in the mother-young relationship. In: Proc. 8th World Rabbit Congr., Puebla (Mexico), pp. 7-10.

Souza, V. M., Batista, G. E., Souza-Filho, N. E. (2015). Automatic classification of drum sounds with indefinite pitch. In: Neural Networks (IJCNN), 2015 International Joint Conference on, IEEE, pp. 1-8.

Souza Filho, N. E., Oliveira, B. C., da Silva, M. L., Vielliard, J. (2014). Automatic classification of Turdus rufiventris song notes by spectrographic image template matching. Ciência e Natura, 36, 646.

\section{Nilson Evilásio Souza Filho}

Engenharia Acústica, Centro de Tecnologia, Universidade Federal de Santa Maria, Santa Maria, RS, Brazil

E-mail: nilson.evilasio@eac.ufsm.br

Participação do autor:

Montagem experimental, monitoramento e classificação dos sons e ensaios de playback

\section{Vinícius Mourão Alves de Souza}

Instituto de Ciências Matemáticas e de Computação, Universidade de São Paulo, São Carlos, São Paulo, Brazil

E-mail: vinicius.email@gmail.com

Participação do autor:

Revisão crítica quanto ao conteúdo intelectual e análise dos dados. 


\section{Ana Carolina Kohlrausch Klinger}

Departamento de Zootecnia, Universidade Federal de Santa Maria, Santa Maria, RS, Brazil

E-mail: aninhaklinger@zootecnista.com.br

Participação do autor:

Concepção, montagem experimental e ensaios de playback. Geni Salete Pinto de Toledo

Departamento de Zootecnia, Universidade Federal de Santa Maria, Santa Maria, RS, Brazil

E-mail: genistoledo@hotmail.com

Participação do autor:

Montagem experimental e supervisão 